KLEINE TEXTE FUOR VORLESUNGEN UND OBUNGEN HERAUSGEGRBEN VON HANS LIBTZMANN

\title{
VULGÄRLATEINISCHES ÜBUNGSBUCH
}

HERAUSGEGEBEN

voN

DR. FRIEDRICH SLOTTY

PRIVATDOZENT IN JENA

\section{BONN}

^ MARCUS UND E. WRBER'S VBRLAG

1918 
Vorliegendes „Vulgărlateinisches Übungsbuch“ bietet proben aus vulgärlateinischen texten des $\mathrm{r}$. -6 . nachchristlichen jahrhunderts. Bei dem gange durch diese jahrhunderte habe ich auf abschnitte der cena Trimalchionis und der Aetheriae peregrinatio nicht verzichten wollen, obwohl sie in der "Sammlung vulgärlateinischer Texte" von W. Heraeus und H. Morf bereits in handlicher form vorliegen. Besonders willkommen wird der abdruck der Appendix Probi III sein, die bisher für übungszwecke schwer erreichbar war. Die probe aus Lucifer Calaritanus, dem „hervorragendsten vertreter des vulgärlateins seiner zeit", liefert zugleich einige stücke der Itala. Einige gedichte des Commodianus und Venantius Fortunatus schaffen gelegenheit $\mathrm{zu}$ metrischen und prosodischen übungen. Das wesentliche dieses büchleins besteht aber in der verbindung der texte mit einer auswahl vulgärlateinischer inschriften; diese, auf lautlicher grundlage in der form eines index angeordnet, sollen das material liefern, lautliche erscheinungen, zu denen die handschriftliche überlieferung der texte eine handhabe bietet, auf gesichertem boden zu erörtern; daneben kōnnen sie aber auch geeigneten stoff zu selbständigen übungen abgeben, da sie ja stets auch andere erscheinungen bieten, auf welche die einordnung die aufmerksamkeit des lernenden nicht hinleitet. Für das selbststudium geben die verweisungen auf $F$. Sommers Handbuch der lateinischen Lautund Formenlehre die nōtigen hinweise.

Dass mir die Diehlschen sammlungen meine aufgabe wesentlich erleichtert haben, erkenne ich dankbar an.

Jena, im Januar 1918.

Fr. SLotTy

\section{INHALTSÜBERSICHT}

I. teil: inschriften zur lautlehre . . . . . . . . . . . . 3

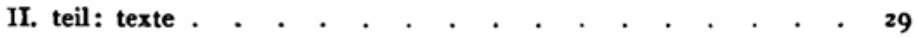

I. Appendix Probi III . . . . . . . . . . . . . . . . . $\quad .29$

2. Petronius Arbiter (sat. XV, 36-46) . . . . . . . 33

3. Lucifer von Calaris (de non parcendo in d. d. cap. 27-29) $4 I$

4. Aetheriae peregrinatio ad loca sancta (cap. $1-7$ ) . . . 46

5. Anthimus (cap. 3. 10-15. 65) . . . . . . . . . 56

6. Commodianus (instr. I, 3. 7. 17. 27. II, 3) . . . . . 59

7. Venantius Fortunatus (carm. I, 20) . . . . . . . 63

Vergleichstabelle zu den inschriften der Diehlschen sammlungen . 64 